generic and reference pMDI should be interchangeable and given the importance of spacer [VHC] use particularly in children, the failure to provide either in vitro or in vivo spacer [VHC] data confirming equivalence would generally preclude regulatory approval of the generic product."

By definition, this recommendation from the drug productregulating agencies appears to preclude the concept of a spacer without evidence of pMDI compatibility within the countries of the European Union. This position is further supported by the very recent recommendation of BLAKE et al. [5]: "VHCs are not interchangeable, as differences in drug delivery to the lung may occur" and "clinicians and pharmacists should be educated not to interchange VHCs once a child is stable on a particular ICS dose and VHC combination."

The problem concerning the prescription of spacers/VHCs without evidence of pMDI compatibility has arisen in Europe because such products have the lowest safety classification as medical devices. Since spacers/VHCs need not be sterile nor do they measure the dose of drug administered, all manufacturers have to do is to "self-declare" compliance to the Medical Devices Directive (MDD) for class 1 devices by means of a Declaration of Conformity. They may then apply the mandatory CE mark directly without further intervention. It is important to note that the purpose of any clinical evaluation that might be undertaken to meet the essential requirements of the MDD is to demonstrate that the device has been designed and manufactured that, when used for the intended purpose, will not compromise the clinical condition or the safety of patients [6]. As such, the evaluation of class I devices does not necessarily mean that a clinical investigation for efficacy and safety takes place, so that the performance of the spacer/VHC need not, therefore, be demonstrated to be pMDI-compatible.

There is abundant published evidence that each pMDIspacer/VHC is a unique inhaled medication delivery system, from in vitro testing of different spacer/VHCs with the same pMDI product and from different pMDI products used with the same spacer/VHC. The clinical evidence for uniqueness with ICSs is less clear [7].

Given the weight of evidence supporting the current regulatory position from the standpoint of the pMDI as the prime drug delivery vehicle, I propose this additional recommendation to the list provided on page 1321 of [1]: "know that each pMDI-spacer is a unique system, and prescribe the spacer named in the Summary of Product Characteristics (where specified by name). In cases where it is not specified in the Summary of Product Characteristics, a different spacer should not be substituted from what is specified by the recommending clinician".

\section{J.P. Mitchell}

Correspondence: J.P. Mitchell, Trudell Medical International, 725 Third Street, London, ON, Canada. E-mail: jmitchell@ trudellmed.com

Statement of Interest: A statement of interest for J.P. Mitchell can be found at www.erj.ersjournals.com/site/misc/statements. xhtml

\section{REFERENCES}

1 Laube BL, Janssens HM, de Jongh FHC, et al. What the pulmonary specialist should know about the new inhalation therapies. Eur Respir J 2011; 37: 1308-1331.

2 Medicines and Healthcare Products Regulatory Agency. Inhaled products that contain corticosteroids. London, MHRA, 2008.

3 European Medicines Agency. Requirements for clinical documentation for orally inhaled products (OIP) including the requirements for demonstration of therapeutic equivalence between two inhaled products for use in the treatment of Asthma and Chronic Obstructive Pulmonary Disease (COPD) in adults and for use in the treatment of asthma in children and adolescents. CPMP/EWP / 4151/00 Rev. 1. London, EMA, 2009.

4 Dissanayake S. Application of the EU guidelines for pharmacokinetic studies of locally acting orally inhaled drug products. Respir Drug Deliv 2010; 1: 293-304.

5 Blake K, Mehta R, Spencer $\mathrm{T}$, et al. Bioavailability of inhaled fluticasone propionate via chambers/masks in young children. Eur Respir J 2012; 39: 97-103.

6 European Parliament. Directive 2007/47/EC of the European Parliament and of the Council of Ministers: Council Directive 93/ 42/EEC concerning medical devices. Off J Eur Union 2007; L247: 21-55.

7 Dolovich MB, Ahrens RC, Hess DR, et al. Device selection and outcomes of aerosol therapy: evidence-based guidelines. Chest 2005; 127: 335-371.

DOI: $10.1183 / 09031936.00210911$

\section{From the authors:}

The European Respiratory Society/International Society of Aerosols in Medicine Task Force thanks J.P. Mitchell for his comments. We agree with his point that the pressurised metered-dose inhaler (pMDI) and spacer, or valved holding chamber (VHC), form a unique system. In the consensus statement [1], we state that "changing the spacer in effect represents a change in the delivery system". We also agree that a different spacer or VHC should not be substituted from that specified by the recommending clinician. We also agree that there can be significant differences in drug output with various commercially available spacers and this may have implications for efficacy, especially with inhaled corticosteroids (ICS) [2]. For this reason, our consensus statement states that "with a change in spacer device, regular monitoring and titration of the ICS dose to the lowest effective dose is advised". However, a clinician may not always choose to prescribe the VHC that is named in the Summary of Product Characteristics (SPC). This may be because different VHCs have been shown to be clinically effective with the same pMDI $[3,4]$, implying that there are different choices for an effective VHC.

There are also differences between countries, since the choices for VHCs in a given country depend on their availability. This means that SPCs may differ between countries. For instance, the fluticasone pMDI is recommended to be used with the Volumatic or the Babyhaler (both GlaxoSmithKline, Brentford, UK) in the Netherlands, but with the Volumatic or the Aerochamber (Trudell Medical International, London, ON, Canada) in the USA. Thus, the importance of the recommendation of the SPC may be relative to an individual country. In addition, because of cost, no VHCs may be available in some developing countries. In those countries, household items such 
as cola bottles have been shown to be an effective substitute for commercially available VHCs [5].

J.P. Mitchell referred to a recently published study of BLAKE et al. [6]. This study showed that there was a two-fold difference in bioavailability between a Babyhaler and an Aerochamber in young children using fluticasone. The authors presumed that electrostatic charge was eliminated because they primed before use. However, electrostatic charge was not measured. Thus, it is possible that it was still present in the VHCs studied by BLAKE et al. [6] and this could account for the difference in bioavailability between devices. Importantly, in vitro data have shown that if electrostatic charge is reduced, the dose to the lungs is more dependent on the pMDI and less on the spacer [7]. Therefore, when electrostatic charge is eliminated, differences between VHCs appear to be reduced.

Differences in spacer dead volume, small tidal volumes and face mask seal can also affect the inhaler dose with a VHC. Thus, a clinician may choose to switch to another VHC when the change may improve therapy in an individual child.

In summary, we agree that pMDI/VHCs form unique combinations. However, clinical practice, patient preference and availability may lead physicians to choose VHCs that are not named in the SPC. This is justified if there is clinical efficacy. For all these reasons, the Task Force has decided not to amend the current recommendations for spacers and VHCs.

\section{H.M. Janssens* and B.L. Laube ${ }^{\#}$ on behalf of the ERS/ISAM Task Force}

*Dept of Pediatric Pulmonology, Erasmus MC/Sophia Children's Hospital, Rotterdam, The Netherlands, and \#Dept of Pediatrics, Johns Hopkins University School of Medicine, Baltimore, MD, USA.
Correspondence: H.M. Janssens, Dept of Pediatric Pulmonology, Erasmus MC/Sophia Children's Hospital, PO Box 2060, 3000 CB Rotterdam, the Netherlands. E-mail: H.Janssens@ erasmusmc.nl

Statement of Interest: A statement of interest for H. Janssens can be found at www.erj.ersjournals.com/site/misc/statements. xhtml

\section{REFERENCES}

1 Laube BL, Janssens HM, de Jongh FHC, et al. What the pulmonary specialist should know about the new inhalation therapies. Eur Respir J 2011; 37: 1308-1331.

2 Wilkes W, Fink J, Dhand R. Selecting an accessory device with a metered-dose inhaler: variable influence of accessory devices on fine particle dose, throat deposition, and drug delivery with asynchronous actuation from a metered-dose inhaler. J Aerosol Med 2001; 14: 351-360.

3 Bisgaard H, Gillies J, Groenewald M, et al. The effect of inhaled fluticasone propionate in the treatment of young asthmatic children: a dose comparison study. Am J Respir Crit Care Med 1999; 160: 126-131.

4 Qaqundah PY, Sugerman RW, Ceruti E, et al. Efficacy and safety of fluticasone propionate hydrofluoroalkane inhalation aerosol in preschool-age children with asthma: a randomized, double-blind, placebo-controlled study. J Pediatr 2006; 149: 663-670.

5 Zar HJ, Brown G, Donson $H$, et al. Home-made spacers for bronchodilator therapy in children with acute asthma: a randomised trial. Lancet 1999; 354: 979-982.

6 Blake K, Mehta R, Spencer $\mathrm{T}$, et al. Bioavailability of inhaled fluticasone propionate via chambers/masks in young children. Eur Respir J 2012; 39: 97-103.

7 Janssens HM, Krijgsman A, Verbraak TF, et al. Determining factors of aerosol deposition for four pMDI-spacer combinations in an infant upper airway model. J Aerosol Med 2004; 17: 51-61.

DOI: $10.1183 / 09031936.00020512$ 